\title{
A Low-Cost Layered Double Hydroxide (LDH) Based Amperometric Sensor for the Detection of Isoproturon in Water Using Carbon Paste Modified Electrode
}

\author{
Herve Leclerc Tcheumi ${ }^{1},{ }^{1,2}$ Aude Peggy Kameni Wendji, ${ }^{1}$ Ignas Kenfack Tonle, ${ }^{1,3}$ \\ and Emmanuel Ngameni ${ }^{1}$ \\ ${ }^{1}$ Laboratoire de Chimie Analytique, Département de Chimie Inorganique, Faculté de Sciences, Université de Yaoundé I, \\ BP 812 Yaoundé, Yaoundé, Cameroon \\ ${ }^{2}$ Laboratoire de Chimie de l'Environnement, Département des Sciences Environnementales, \\ Ecole Nationale Supérieure Polytechnique de Maroua, Université de Maroua, BP 46 Maroua, Maroua, Cameroon \\ ${ }^{3}$ Laboratoire de Chimie Minérale, Département de Chimie, Faculté des Sciences, Université de Dschang, BP 67 Dschang, \\ Dschang, Cameroon
}

Correspondence should be addressed to Herve Leclerc Tcheumi; herveleclerc@yahoo.fr

Received 18 February 2020; Revised 4 July 2020; Accepted 30 July 2020; Published 21 August 2020

Academic Editor: Jose Vicente Ros Lis

Copyright (c) 2020 Herve Leclerc Tcheumi et al. This is an open access article distributed under the Creative Commons Attribution License, which permits unrestricted use, distribution, and reproduction in any medium, provided the original work is properly cited.

In this work, a Layered Double Hydroxide (NiAl-LDH) was obtained by coprecipitation method and used to elaborate an electrochemical sensor for the determination of isoproturon, which is a hazardous pollutant, widely used in agriculture, and its residue is distributed into aqueous environment through run-off and leaching from the soil. Various physicochemical techniques such as FT-IR spectroscopy, X-ray diffraction, and thermal analysis were used to characterize this material. The anionic exchange capacity of NiAl$\mathrm{LDH}$ on carbon paste modified electrode was investigated toward $\left[\mathrm{Fe}(\mathrm{CN})_{6}\right]^{3-}$ using cyclic voltammetry. Used as electrode modifier of carbon paste electrode for isoproturon detection, a remarkable increase in isoproturon signal on modified carbon paste electrode by $\mathrm{LDH}$ was observed. The peak current obtained after $3 \mathrm{~min}$ of preconcentration in $25 \mu \mathrm{M}$ ISO on NiAl-LDH/CPE was 2.6 times higher than that exhibited by the same analyte on the unmodified CPE, thereby opening the way to the development of a sensitive method for the detection of ISO. Other parameters that can affect the stripping response (preconcentration time, $\mathrm{pH}$ of detection medium, and LDH loading within the paste) were investigated to optimize the proposed sensor. After optimization, a linear calibration curve was obtained in the concentration range from $2 \times 10^{-8}$ to $1.8 \times 10^{-7} \mathrm{M}$, leading to a detection limit of $1 \times 10^{-9} \mathrm{M}(\mathrm{S} / \mathrm{N}=3)$. The relative standard deviation for 5 identical measurements was $2.7 \%$. The interfering effect of some compounds and ions was examined on the stripping response of ISO. The applicability of the method was verified by the determination of ISO in spiked water sample.

\section{Introduction}

Isoproturon [3-(4 isopropylphenyl)-1,1-dimethylurea, referred to as ISO hereafter] is a phenylurea herbicide widely used for pre- and postemergence control of annual grasses and broadleaved weeds in spring and water cereals [1]. Progressive increase in the production and application of ISO for plant protection induces the problem of water quality due to the long time taken by this class of compounds to degrade [2]. The intensive use of phenylurea herbicides as ISO in agriculture results in a high risk of these herbicides entering the food chain by means of contaminated water [3]. Its residues can cause severe health effects in both human and animals upon its absorption [4], due to its chronic toxicity, carcinogenicity, and genotoxicity [5]. Therefore, sensitive determination of ISO is highly important. Up to now, several techniques have been reported for phenylurea herbicides determination; they include ultraviolet spectroscopy [5], capillary electrophoresis [3,6], and mainly gas or liquid chromatography $[7,8]$. Nevertheless, these methods are not easy to carry out because they often necessitate long analysis times and require several preprocessing steps and expensive equipment. Additionally, these methods are not 
sensitive. Therefore, the development of simple, low cost, and sensitive methodologies for monitoring of pesticides remains a daily concern. Following these lines, electrochemical analysis has significant advantages such as speediness and less expensive instrumentation. However, the unmodified electrodes suffer from drawbacks such as high overpotential and electrodes surfaces fouling issues. As such, finding suitable electrode modified for determination of organic pollutants is an interesting research. In that context, Sundari and Manisankar [9] elaborated a modified electrode by coating multiwalled carbon nanotube film on a glassy electrode for electrochemical determination of ISO; Noyrod et al. [10] reported a simultaneous determination of ISO and carbendazim by single drop analysis using a graphene-based electrochemical sensor. Promising research results have been obtained with electrodes modified with Layered Double Hydroxides (LDHs) for electroanalysis of organic and inorganic pollutants as have also been explored [11-14], because of their ability to accumulate various chemical species in their interlayer region. In fact, LDHs are the class of host-guest type layered material consisting of positively charged metal hydroxide layers acting with free hydrated anions located in the interlayer space. A general formula for the most widely studied LDHs is $\left[\mathrm{M}^{\mathrm{II}}{ }_{1-\mathrm{x}} \mathrm{M}^{\mathrm{III}}{ }_{\mathrm{x}}(\mathrm{OH})_{2}\right]^{\mathrm{x}+} \cdot\left[\left(\mathrm{A}^{\mathrm{n}-}\right)_{\mathrm{x} / \mathrm{n}}\right.$. $\mathrm{mH}_{2} \mathrm{O}$ ] where $\mathrm{M}^{\mathrm{II}}$ can be $\mathrm{Mg}^{2+}, \mathrm{Mn}^{2+}, \mathrm{Ni}^{2+}$, etc., while $\mathrm{M}^{\mathrm{III}}$ may be $\mathrm{Al}^{3+}, \mathrm{Mn}^{3+}, \mathrm{Cr}^{3+}$, etc. $\mathrm{A}^{\mathrm{n}-}$ represents an intercalable anion, and $\mathrm{x}$ is the molar ration. Recently, considerable interest has been diverted to the study of the adsorption of environmental contaminant by LDH materials [15]; however, most of them were focused on the adsorption of anion pollutants. As a result, it is necessary to design and synthesize adsorbents based on $\mathrm{LDH}$ materials for adsorption of neutral pollutants.

Several approaches have been used to synthetize LDH; these include coprecipitation hydrothermal method, urea hydrolysis, and electrodeposition [16]. Nevertheless, coprecipitation is a technique that is widely used to make batches materials due to its relative simplicity and ease of use of the resulting material for adsorption of pollutant in batch adsorption mode [17]. The development of electrochemical sensors for ISO at trace level has attracted an increasing interest in the last decade. Different methods have been proposed to modify electrode surface with LDH film $[12,13]$; the most common one consists of depositing a fixed amount of a colloidal solution of the $\mathrm{LDH}$, previously synthesized in bulk by the coprecipitation method [18], onto the support. This method suffers a drawback of poor adhesion of the film to the support material, thus lacking the reproducibility of the results obtained. To overcome of this weakness of film modifier electrode, Carbon Pate Electrode (CPE) presents interesting alternative. In fact, carbon paste electrode possesses many advantages which include low background current, rapid and confortable renewal of the active surface of the electrode, and easy fabrication and modification with a wide range of compounds. Investigations dealing with the use of $\mathrm{LDH}$ as modifier of CPE for sensing of pollutant are not widespread. To overcome these, numerous attempts have been made. For example, Fuerte et al. [11] investigated the electrochemical oxidation of 4-chlorophenol using CPE modified with ZnAl-LDH and Isa et al. [14] used multiwalled carbon nanotube modified with $\mathrm{ZnAl}-\mathrm{LDH}$ to prepare chemically modified carbon for $\mathrm{Hg}^{2+}$ determination.
This study designed and developed an electrochemical sensor for ISO detection using CPE modifier electrode with $\mathrm{NiAl}-\mathrm{LDH}$. The ISO retention by NiAl-LDH was through $\mathrm{H}$-bonding between the hydroxyl group NiAl-LDH and amide group of ISO. This type of interaction can contribute to the enhancement of the sensitivity of ISO during the detection step. NiAl-LDH synthetized was fully characterized (FT-IR, XRD, and TGA) prior to their application as electrode material and used for the development of a sensitive sensor dedicated to the electrochemical determination of ISO in water samples.

\section{Experimental Methods}

2.1. Chemicals and Reagents. All chemicals and reagents used in this work were of analytical grade and used as received. ISO was purchased from Supelco, France, and $10^{-2} \mathrm{M}$ stock solutions were prepared in methanol. $\mathrm{K}_{3} \mathrm{Fe}(\mathrm{CN})_{6}$ (>99\%, Prolabo) was reagent grade and used as received. An acetate buffer solution was used as supporting electrolyte and was prepared by mixing $0.1 \mathrm{~mol} \mathrm{~L}^{-1} \mathrm{CH}_{3} \mathrm{COONa}$ and $\mathrm{CH}_{3} \mathrm{COOH}$ (Riedel-de-Haen). The $\mathrm{pH}$ of solution was adjusted using molar $\mathrm{NaOH}$ and $\mathrm{HNO}_{3}$ solutions prepared from analytical reagents purchased, respectively, from $\mathrm{BDH}$ and Prolabo. All the aqueous solutions were prepared using deionized water.

\subsection{Synthesis of NiAl-LDH and Their Characterization.} The synthesis of NiAl-LDH by a conventional coprecipitation method was adapted to the method previously reported [19]. In practice, an aqueous solution of nickel nitrate and aluminum nitrate in the molar ratio $3 / 1$ was prepared by dissolving, respectively, $0.0045 \mathrm{~mol}$ and $0.015 \mathrm{~mol}$ of these compounds in $100 \mathrm{ml}$ of deionized water, the ph being maintained constant at $10.1 \pm 0.5$ by the addition of a sodium hydroxide solution $(2 \mathrm{~m})$. The synthesis was carried out using boiling water and under nitrogen atmosphere in order to minimize the contamination with atmospheric $\mathrm{CO}_{2}$. The resulting suspension was then stirred for $16 \mathrm{~h}$ and filtered and the solid obtained was collected, washed, and dried in an oven at $70^{\circ} \mathrm{C}$ for $24 \mathrm{~h}$.

NiAl-LDH was subsequently characterized by X-ray powder diffraction (XRD), Fourier Transform Infrared (FTIR), and thermal analysis.

XRD patterns were recorded at room temperature using a classical powder diffractometer (X'PERT PRO, Philips) equipped with a $\mathrm{Cu}$ anode (quartz monochromator, $\mathrm{k} \alpha_{1}$ radiation, $\lambda=1.54056 \AA$ ).

Diffuse reflectance infrared spectra were recorded between 4000 and $500 \mathrm{~cm}^{-1}$, using a FT-IR Perkin Elmer 2000 spectrometer equipped with a DTGS detector. The sample was analyzed at room temperature using $\mathrm{KBr}$ pellets. The diffuse reflectance $R_{s}$ of the sample and $R_{r}$ of $K B r$ used as nonabsorbing reference powder were measured in the same conditions. The spectrum resolution was $4 \mathrm{~cm}^{-1}$ and the accumulation time was $5 \mathrm{~min}$.

Thermal Gravimetric Analysis (TGA) was performed on a SDT simultaneous DSC-TGA instrument under $\mathrm{N}_{2}$ flow 
$\left(100 \mathrm{~mL} \cdot \mathrm{min}^{-1}\right)$. Approximately $20 \mathrm{mg}$ of the NiAl-LDH was placed on the thermobalance of analyzer, which was purged with helium gas.

2.3. Working Electrode Preparation, Electrochemical Equipment and Procedures. The preparation of CPE modified by LDH (namely, NiAl-LDH/CPE) was similar to the procedures previously described [20]. Briefly, CPE was obtained by intimately mixing a carbon powder from Alfa (particle size $<325$ mesh), a pasting liquid (silicone oil, Prolabo), and LDH particles $(60-30-10 \% \mathrm{w} / \mathrm{w})$. The mixture was homogenized in a mortar for $40 \mathrm{~min}$ and placed in a cylindrical Teflon tube (6 $\mathrm{mm}$ internal diameter), equipped with a stainless steel screw and piston acting as the electrical contact. The active surface of the electrode was then polished on a sheet of clean paper.

The electrochemical measurements were performed on a $\mu$-Autolab potentiostat controlled by the GPES software. Cyclic voltammetry was used to examine the electrochemical behavior of ISO, while square wave voltammetry was employed to optimize the sensitivity of sensor. Electrochemical procedure for sensing ISO was as follow: the modified electrode was dipped in a beaker containing $25 \mu \mathrm{M}$ of aqueous solution of ISO $(50 \mathrm{~mL})$ and maintained under mild stirring for $5 \mathrm{~min}$ for accumulation at open circuit. After this step, the electrode was removed, rinsed with distilled water, and then transferred to the electrochemical cell containing the detection solution. Prior to the SWV experiment, the detection medium was deaerated with nitrogen for $3 \mathrm{~min}$. The regeneration of sensor was made by transferring the modified electrode (after detection) to a blank acetate solution under mild stirring. The trace amounts of ISO were totally desorbed after $1 \mathrm{~min}$, shown by a flat voltammogram recorded after transferring the electrode from the detection medium.

\section{Results and Discussions}

3.1. Physicochemical Characterization of the NiAl-LDH. Figure 1(a) shows the FT-IR spectra of NiAl-LDH. A large absorption band which is centered at $3427 \mathrm{~cm}^{-1}$ corresponds to the stretching vibrations mode of hydrogen bonded physisorbed and intercalated water molecules [21]. Similarly, the band close to $1640 \mathrm{~cm}^{-1}$ corresponds to the $\mathrm{O}-\mathrm{H}$ bending vibration of the interlayer water [22]. The intense band at $1383 \mathrm{~cm}^{-1}$ is due to the $\mathrm{V}_{3}$ vibration mode of nitrate ion in $\mathrm{D}_{3 \mathrm{~h}}$ symmetry present in the interlayer space [23]. The band characteristic to metal-oxygen bond stretching appears at $644 \mathrm{~cm}^{-1}$ and $540 \mathrm{~cm}^{-1}$ is caused by various lattice vibrations associated with metal hydroxide sheets [24].

The XDR pattern of NiAl-LDH is presented in Figure 1(b). The peaks at $11.03^{\circ}$ and $22.7^{\circ} 2 \theta$ are assigned to the 003 and 006 reflections, respectively [25]. The first peak corresponds to a $\mathrm{d}_{003}$ value of $8.2 \AA$. Also noted is the presence of well-defined reflections-012, 110, and 113-that are frequently used to confirm the good crystallinity of LDH [26].

The result of thermal analysis of material is presented in Figure 1(c). NiAl-LDH displayed a progressive mass loss of
$15 \%$ in the temperature range between $20^{\circ} \mathrm{C}$ and $190^{\circ} \mathrm{C}$, which is attributed to the loss of water molecules adsorbed on the external surface of NiAl-LDH or in the interlayer surfaces. From $250^{\circ} \mathrm{C}$ to $450^{\circ} \mathrm{C}$, significant mass losses (25\%) in two stages were observed, corresponding to the dehydroxylation and the loss of nitrate ions [27, 28]. The first event is fast and characterized by a well-defined DTG with a peak at $327^{\circ} \mathrm{C}$, while the second is much slower with a broad and poorly defined peak centered at $400^{\circ} \mathrm{C}$.

3.2. Electrochemical Characterization of NiAl-LDH. In order to explore the possible use of the NiAl-LDH material as modifier of $\mathrm{CPE}$, some preliminary experiments were performed using $\left[\mathrm{Fe}(\mathrm{CN})_{6}\right]^{3-}$ ions as electroactive probe. The reactivity of a material at a given modified electrode strongly depends on the properties of that material. Thus to get precise information about this material ion exchange voltammetry was used. This was done by examining the electrochemical behavior of $\left[\mathrm{Fe}(\mathrm{CN})_{6}\right]^{3-}$ ions at modified and unmodified carbon paste electrode, by recording a series of cyclic voltammograms. Figure 2 displays multisweep cyclic voltammograms recorded at bare CPE (Figure 2(a)) and NiAl-LDH/CPE (Figure 2(b)). At bare CPE, well-defined diffusion controlled redox behaviors with $\left[\mathrm{Fe}(\mathrm{CN})_{6}\right]^{3-}$ with a constant steady state were recorded upon repetitive scanning. The cyclic voltammogram recorded at bare CPE were centered at $E^{\circ}=1 / 2\left(E_{p c}+E_{p a}\right)=0.245 V$ with peak to peak separation values of $\Delta \mathrm{Ep}=\left(\mathrm{E}_{\mathrm{pa}-} \mathrm{E}_{\mathrm{pc}}\right)=0.09 \mathrm{~V}$ at scan $50 \mathrm{mV} /$ $s$ and the magnitude of $i_{p a} / i_{p c}$ is equal to 1.09 ; this value suggests a reversible electrochemical system as a result of monoelectronic transformation involving $\left[\mathrm{Fe}(\mathrm{CN})_{6}\right]^{3-}$ and $\left[\mathrm{Fe}(\mathrm{CN})_{6}\right]^{4-}$. When the electrode was modified by NiAl$\mathrm{LDH}$, the multisweep cyclic voltammetry performed on the same probe solution led to a different behavior as shown in Figure 2(b). During the first scan, a poor signal was observed due to the effect caused by nonconductive NiAl-LDH material. Since this material is an excellent anionic exchanger, gradual increase in the intensities of the signals with the number of scan is observed. The peak current reaches its maximum value after 40 cycles and the current was 49 times higher than that recorded for the unmodified CPE. The peak to peak separation recorded at NiAl-LDH/CPE was $0.045 \mathrm{~V}$. This value was lower for about $45 \mathrm{mV}$ compared with that obtained at bare CPE, suggesting that the diffusion of the probe is easy at modified electrode. This result is a proof that NiAl-LDH accumulates $\left[\mathrm{Fe}(\mathrm{CN})_{6}\right]^{3-}$ ions by anion exchange mechanism $[29,30]$.

The active area of electrodes was studied using Randles-Sevcik equation. The cyclic voltammetry at varying sweep rates was recorded using $\mathrm{K}_{3}\left[\mathrm{Fe}(\mathrm{CN})_{6}\right]$ solution $10^{-3} \mathrm{M}$ in $\mathrm{KCl}$ solution $0.1 \mathrm{M}$. From the slope of the plot of Ip vs. $\nu 1 / 2$ (Figure $\mathrm{S} 1$ ), the A value was calculated using the following equation:

$$
i_{p}=\left(2.69 .10^{5}\right) D_{0} n^{(3 / 2)} C_{0} A \text {. }
$$

Here, for $\left[\mathrm{Fe}(\mathrm{CN})_{6}\right]^{3-}=10^{-3} \mathrm{M}, \mathrm{D}_{\mathrm{o}}=7.6 .10^{-6} \mathrm{~cm}^{2} / \mathrm{s}$, and $n=1$, the calculated effective surface areas were found to be $0.047 \mathrm{~cm}^{2}$ and $0.055 \mathrm{~cm}^{2}$ for bare CPE and with NiAl-LDH/ $\mathrm{CPE}$, respectively. 


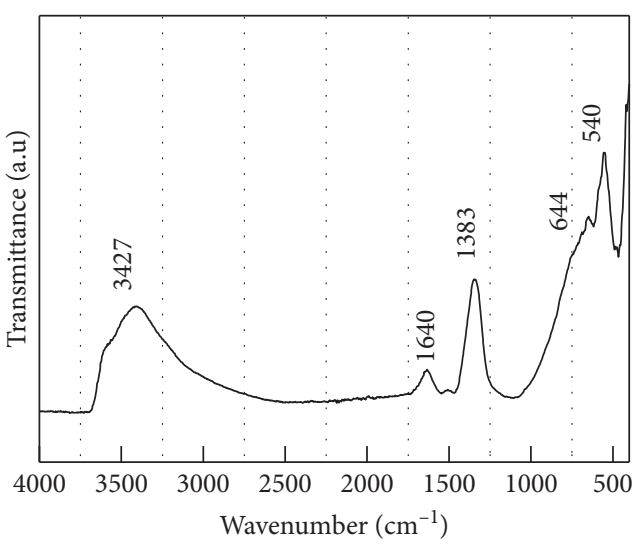

(a)

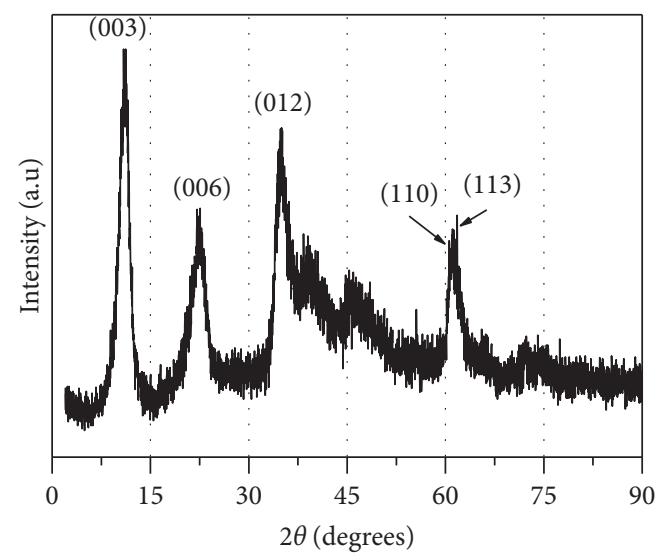

(b)

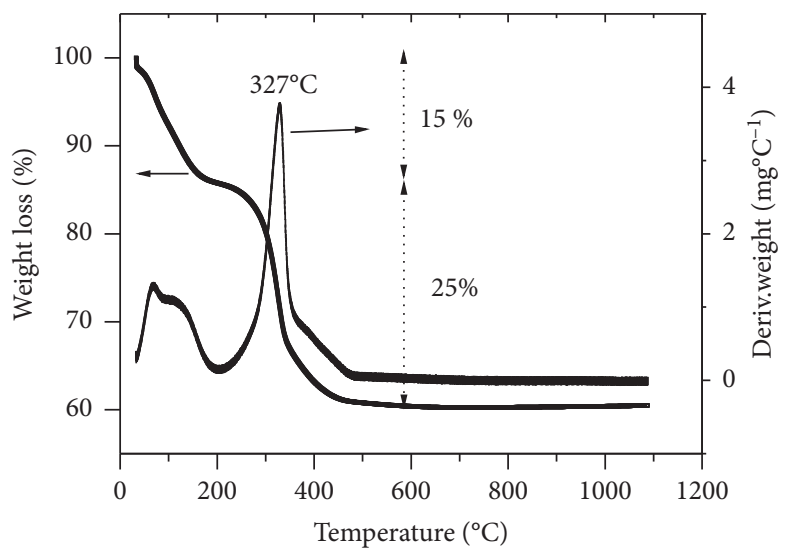

(c)

FIGURE 1: (a) Infrared spectra (4000-500 $\mathrm{cm}^{-1}$ region); (b) X-ray diffraction; (c) TG and DTG patterns of NiAl-LDH.

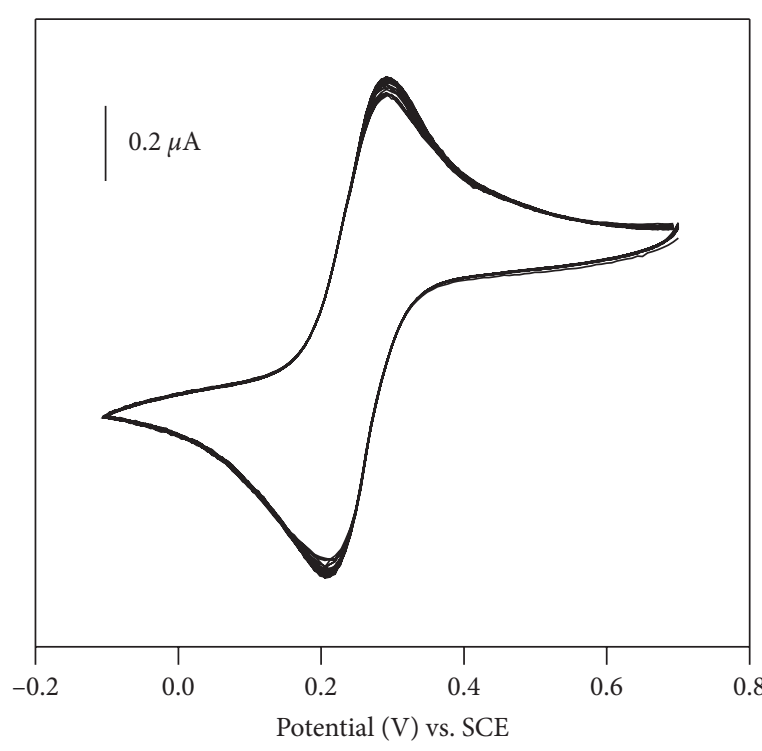

(a)

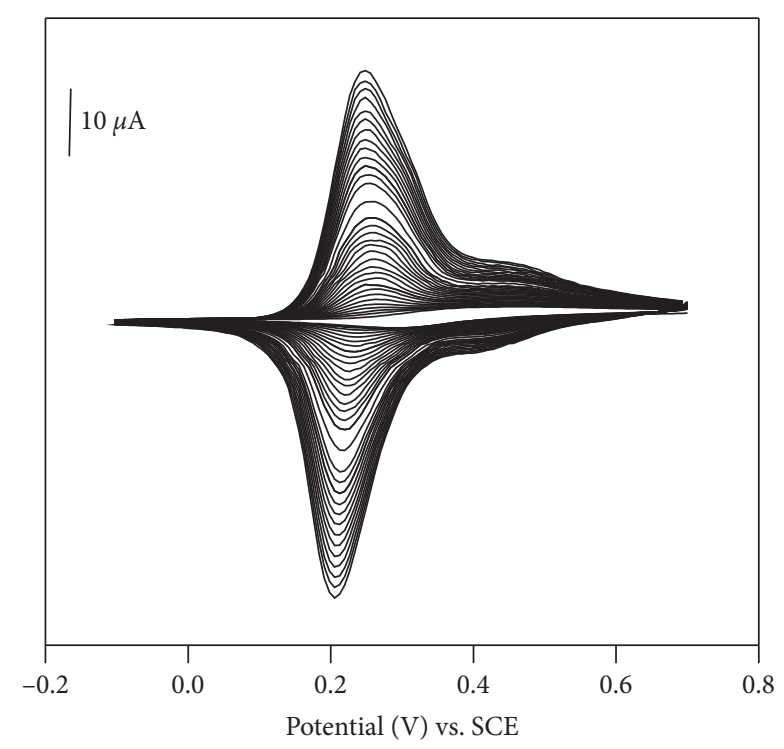

(b)

Figure 2: Multisweep cyclic voltammograms recorded at $50 \mathrm{mV} \mathrm{s}^{-1}$ in $\mathrm{NaCl} 0.1 \mathrm{M}+10^{-4} \mathrm{M}$ of $\left[\mathrm{Fe}(\mathrm{CN})_{6}\right]^{3-}:$ (a) CPE; (b) NiAl-LDH/CPE. Scan rate $50 \mathrm{mV} / \mathrm{s}$. 


\subsection{Electrochemical Behavior of Isoproturon on NiAl-LDH/} $C P E$. Cyclic voltammogram of $50 \mu \mathrm{M}$ of ISO in acetate buffer at CPE and NiAl-LDH/CPE was recorded as shown in Figure 3(a). The blank cyclic voltammogram obtained at $\mathrm{NiAl}-\mathrm{LDH} / \mathrm{CPE}$ in acetate buffer is included (dotted line). In both cases, the electrochemical response shows one main anodic peak centered on $0.9 \mathrm{~V}$. Such electrochemical behavior of ISO was similar to previous work described in the literature with phenylurea compound such as diuron and fenuron [3, 31]. The equation of this transformation was illustrated by (2) [32]. From this cyclic voltammogram, it is obvious that oxidation peak current is greater for NiAl$\mathrm{LDH} / \mathrm{CPE}$ than EPC. The peak current on NiAl-LDH/CPE was 3.25 times higher than that recorder on $\mathrm{CPE}$, indicating an effective preconcentration ability of ISO by NiAl-LDH/ $\mathrm{CPE}$. The increase in peak current may be due to adsorptive ability of NiAl-LDH through hydrogen bonding between hydroxyl group of NiAl-LDH and amide group of ISO.

$$
\left(\mathrm{H}_{3} \mathrm{C}\right)_{2} \mathrm{HC}-\left(\mathrm{H}_{3} \mathrm{C}\right)_{2} \mathrm{HC} \longrightarrow \stackrel{\mathrm{NH}-\mathrm{II}}{\mathrm{C}}-\mathrm{N}\left(\mathrm{CH}_{3}\right)_{2} \frac{2 \mathrm{H}^{+}}{-2 \mathrm{e}^{-}} \longrightarrow \mathrm{NH}_{2}+\mathrm{CO}+\mathrm{NH}\left(\mathrm{CH}_{3}\right)_{2}
$$

In order to yield more insights in the electrochemical behavior of ISO, further experiments were performed; these include the studying of the effect of increasing the potential scan rate. From Figure 3(b), it appears that the peak current increases with the potential scan rate. A plot of the anodic peak current versus $\mathrm{V}^{1 / 2}$ exhibits a linear dependence as indicated by the graph in Figure 3(b), indicating that electrochemical oxidation takes place via adsorption with mass transfer [32]. From the above cyclic voltammetry studied, it appears that NiAl-LDH used as electrode modifier can be suitable for building an electrochemical sensor for ISO.

Figure 4 presents the SWV curves of acetate buffer solution at a CPE (Figure 4(a)) and $25 \mu \mathrm{M}$ ISO in acetate solution at a CPE (Figure 4(b)) or NiAl-LDH/CPE (Figure 4(c)). A well-defined but rather low peak was obtained in the potential range of 0.5 to $1.1 \mathrm{~V}$ with CPE (Figure 4(b)) pointing out the weak sorption capacity of the carbon towards ISO. When the CPE was modified by NiAl-LDH, its sensitivity was significantly improved (Figure 4(c)). The peak current measured was found to be equal to $13 \mu \mathrm{A}$; this value is more than 2.6 times higher than that recorded at CPE $(5 \mu \mathrm{A})$.

Some important physicochemical parameters involved in the stripping process were examined in order to optimize the sensitivity of the modified electrode, in view of its possible use as ISO sensor. Prior to this study, the stability and reproducibility of the signal of ISO on the NiAl-LDH/CPE were evaluated before its application to the voltammetric detection of ISO. Thus, a series of five successive SWV experiments of the same electrode were performed in $25 \mu \mathrm{M}$ of ISO solution (Figure 5), and a coefficient of variation of $2 \%$ was noticed, indicating that the modified electrode has good reproducibility. The stability of the electrode was also investigated by measuring the electrode response with $25 \mu \mathrm{M}$ of ISO every day. Between the measurements, the electrode was stored at $4^{\circ} \mathrm{C}$ in a refrigerator. The current response decreases to $5 \%$ after 5 days.

\subsection{Optimization of Experimental Parameters for ISO Detection}

3.4.1. Influence of the Accumulation Time. The effect of accumulation time is shown in Figure 6(a). The peak current increased gradually with the accumulation time up to $150 \mathrm{~s}$.
Afterwards, the peak current increased much slightly as with further increase in the accumulation time. This phenomenon could be attributed to the saturated adsorption of ISO on NiAl-LDH/CPE. Considering sensitivity, the optimal accumulation time of $150 \mathrm{~s}$ was employed in further experiments.

3.4.2. The Effect of NiAl-LDH Amount on the Paste Composition. The study of the effect of NiAl-LDH proportion within the CPE was also expected to affect the electrode response. Figure 6(b) presents the evolution of the SWV peak current when the detection of ISO was performed with NiAl$\mathrm{LDH} / \mathrm{CPE}$ prepared with various amounts of NiAl-LDH. The peak current was shown to increase with the amount of NiAl$\mathrm{LDH}$ incorporated in the paste, up to a maximum value of $10 \%$. This was followed by the decrease of the current for higher amount of LDH within the paste. From $2.5 \%$ to $10 \%$, the increase on peak current was due to the number of adsorption sites, which increases at the solution electrode interface. The reduction of peak current observed at $12 \%$ is due to the fact that LDHs are weakly conductive material. The high amount of this modifier within the carbon paste reduced the conductivity of the electrode [33]. The optimum percentage of NiAl-LDH/CPE incorporated into the CPE was chosen to be $10 \%$ due to the best compromise between the number of sites and the conductivity of the paste.

3.4.3. Influence of the $p H$ of the Detection Medium. The acidity of the detection medium is a key parameter that can affect the mass transport to the electrode surface, especially when the redox process involves some protons as in the present case. The influence of the $\mathrm{pH}$ on the ISO response was studied at NiAl-LDH/CPE between $\mathrm{pH} 1$ to 6 , because ISO can be partially hydrolyzed in alkaline medium [32]. It is observed from Figure 6(c) that the peak current increased with an increase of $\mathrm{pH}$ of the detection medium to a maximum value at $\mathrm{pH}$ 4.5. After this value, the decrease of sensibility with increase of $\mathrm{pH}$ value was observed. For higher $\mathrm{pH}$ values, low current value was observed. The low electrode response obtained for $\mathrm{pH}<2$ may be due to prior protonation of amino group in the substrate, which induces electrostatic repulsion between the analyte and $\mathrm{NiAl}-\mathrm{LDH}$ edges layer 


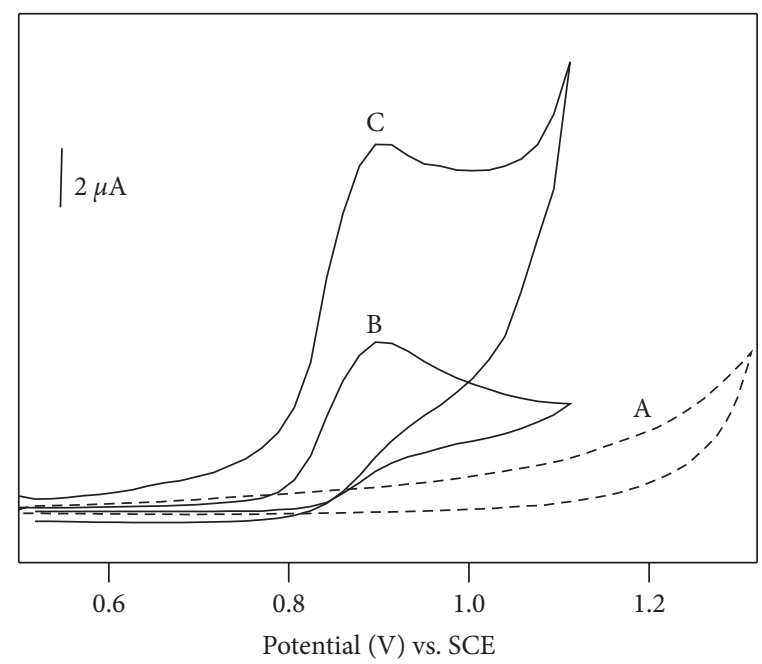

(a)

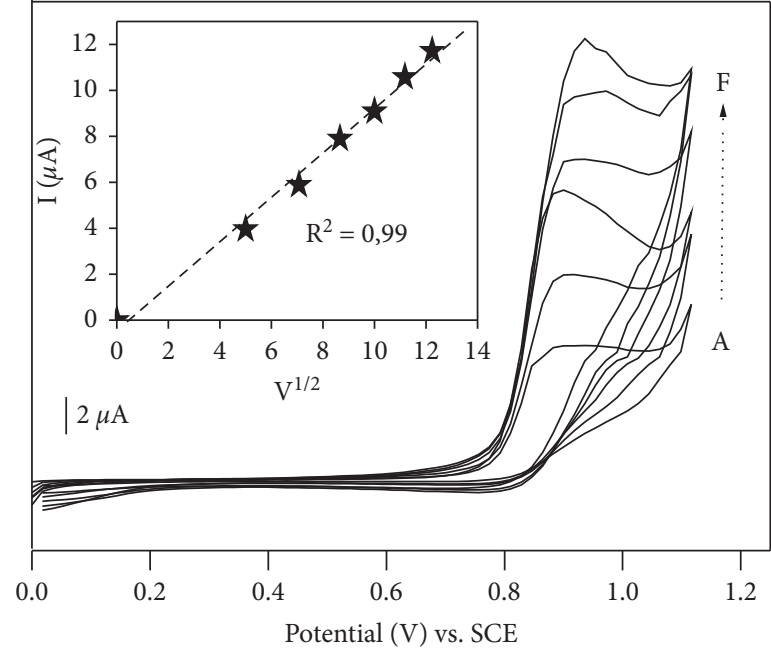

(b)

Figure 3: (a) Cyclic voltammograms recorded on (A) NiAl-LDH/CPE in $0.1 \mathrm{M}$ acetate buffer (pH 4.5); (B) on CPE in $50 \mu \mathrm{M}$ ISO + 0.1 M acetate buffer ( $\mathrm{pH} 4.5$ ); (C) on NiAl-LDH/CPE in $50 \mu \mathrm{M}$ ISO + $0.1 \mathrm{M}$ acetate buffer ( $\mathrm{pH} 4.5$ ); potential scan rate $50 \mathrm{mV} \mathrm{s}^{-1}$. (b) Influence of scan rate (v) on peak current of $50 \mu \mathrm{M}$ of ISO on the NiAl-LDH/CPE (curves a-f, $v=25,50,75,100,125$, and 150 mv.s ${ }^{-1}$, respectively). Inset: plot of the anodic peak current $\left(\mathrm{Ip}_{\mathrm{a}}\right)$ versus $\mathrm{v}^{1 / 2}$.

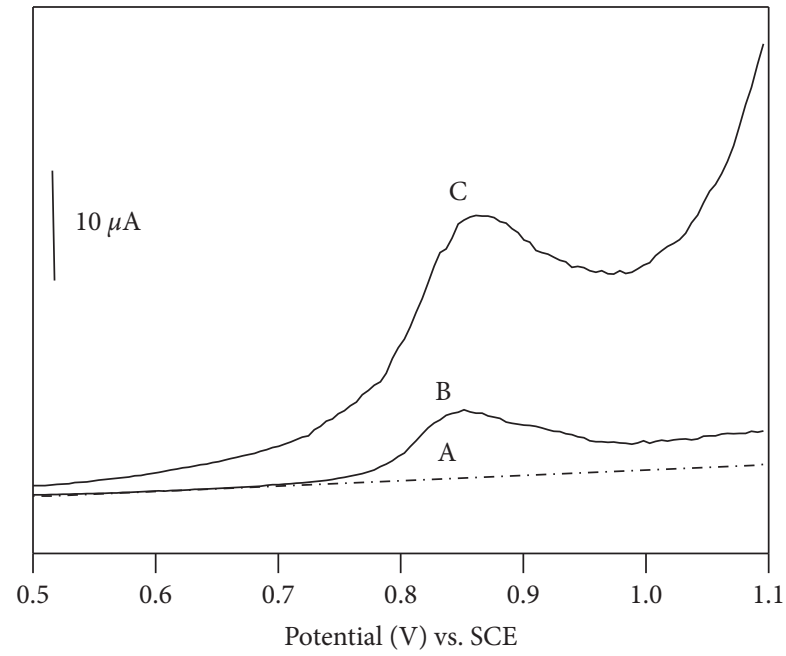

FIgURE 4: SWV response of (a) $0.1 \mathrm{M}$ acetate buffer on CPE; (b) ISO $25 \mu \mathrm{M}$ after $3 \mathrm{~min}$ accumulation and detection in $0.1 \mathrm{M}$ acetate buffer on CPE; (c) ISO $25 \mu \mathrm{M}$ after $3 \mathrm{~min}$ accumulation and detection in $0.1 \mathrm{M}$ acetate buffer on NiAl-LDH/CPE. Other experimental conditions: electrolysis potential: $0.8(\mathrm{~V})$ pulse amplitude: $50 \mathrm{mV}$, frequency $125 \mathrm{~Hz}$.

which contains positive charge. The sensibility of the electrode is optimal at $\mathrm{pH}$ 4.5. The lower stripping signal recorded for $\mathrm{pH}>4.5$ must probably be due to the quantity of $\mathrm{OH}^{-}$in the medium which can react by exchange mechanism with exchanger ion in the interlayer, thus contributing to the reduction of the sensibility of the electrode.

The relationship between the oxidation peak potential and $\mathrm{pH}$ was shown in Figure 6(d). A linear shift of $\mathrm{E}_{\mathrm{pa}}$ towards negative potential with an increasing $\mathrm{pH}$ indicated that protons are directly involved in the oxidation of ISO. It

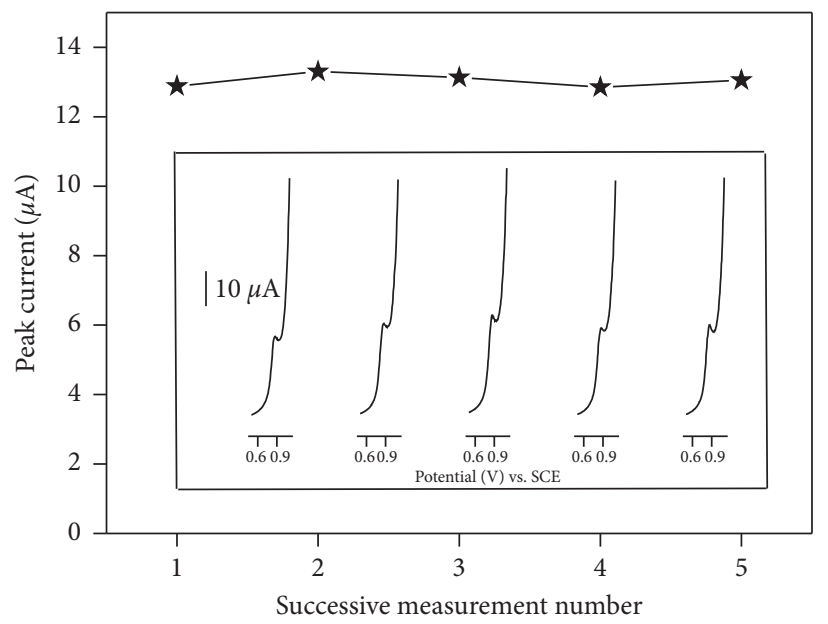

FIGURE 5: Typical successive peaks recorded using $25 \mu \mathrm{M}$ of ISO after $3 \mathrm{~min}$ accumulation and detection in $0.1 \mathrm{M}$ acetate buffer on $\mathrm{NiAl}-\mathrm{LDH} / \mathrm{CP}$; inset SWV response recorded in condition the same as in Figure 3.

obeys the following equation: $\mathrm{E}_{\mathrm{pa}}(\mathrm{V})=-0.025 \mathrm{pH}+0.974$. The slope of the variations in Ep vs. pH, of $0.025 \mathrm{~V} / \Delta \mathrm{pH}$, suggests that the same numbers of protons and electrons are involved in the electrochemical oxidation of ISO, almost matching the theoretical Nernst equation [34].

3.4.4. Influence of the SWV Technique Parameters. Square wave parameters are also important in controlling the peak intensity. These parameters include the frequency, the electrolysis potential, and amplitude. All these parameters were studied and the most suitable values used for the detection of ISO are given in Table 1. 


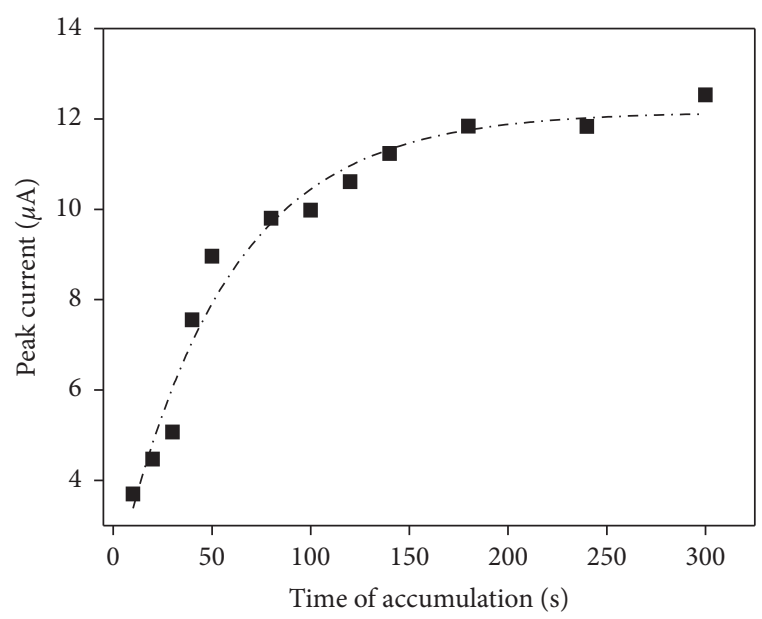

(a)

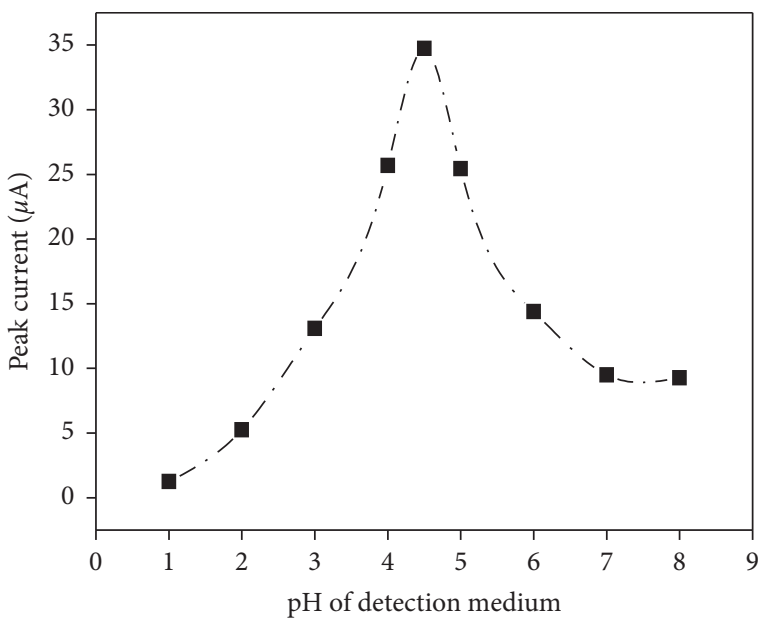

(c)

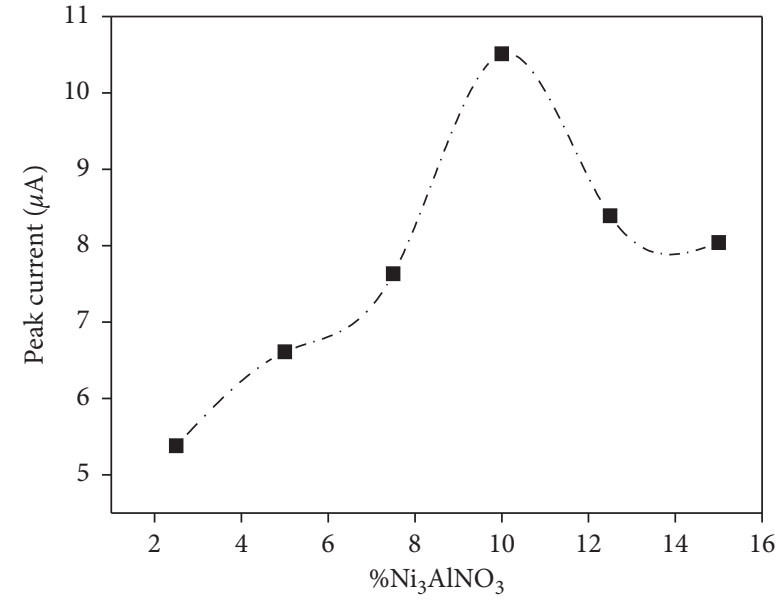

(b)

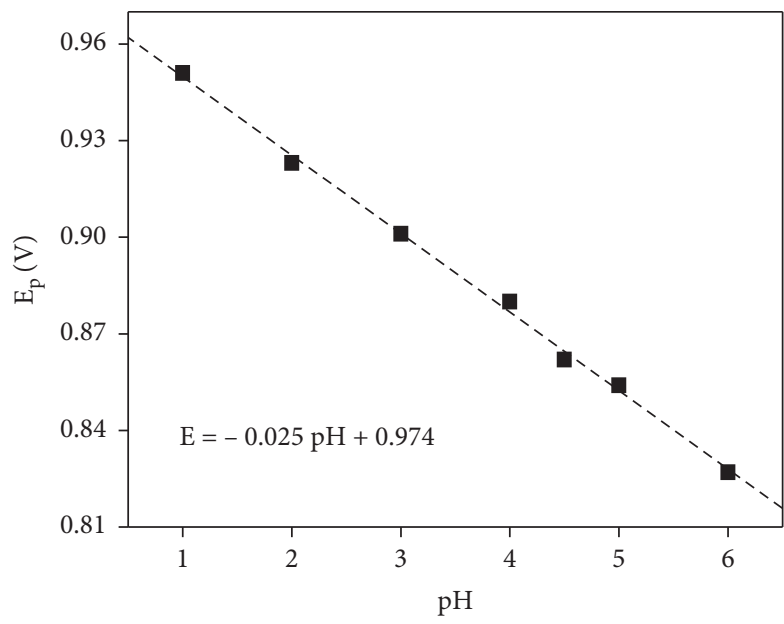

(d)

FIGURE 6: (a) Effect of accumulation time on the peak current of ISO; (b) effect of the amount of NiAl-LDH in the composition of the paste on the peak current of ISO; (c) effect of $\mathrm{pH}$ of detection medium on the peak current of ISO; (d) variation of the peak potential versus $\mathrm{pH}$ of the detection medium. Other conditions are the same as in Figure 4.

3.4.5. Interference Studies. Under optimal experimental conditions, the effects of other coexisting substances and anions were studied. The results summarized in Table 2 show that 5-fold excess of $\mathrm{Cl}^{-}, \mathrm{NO}_{3}{ }^{-}$, and $\mathrm{HCO}_{3}{ }^{-}$did not interfere with the analysis of ISO. However, when the concentration of these ions increases up to 50 -fold excess $\left(\mathrm{Cl}^{-}, \mathrm{NO}_{3}{ }^{-}\right.$, and $\mathrm{HCO}_{3}{ }^{-}$), they interfere with the analysis of ISO by increasing the peak current due to the ion exchange properties of NiAlLDH. We have also studied the effect of cations $\left(\mathrm{Al}^{3+}, \mathrm{Pb}^{2+}\right)$. The results obtained show that $\mathrm{Al}^{3+}$ and $\mathrm{Pb}^{2+}$ were found to interfere slightly at 50-fold excess with the analysis of ISO. The effect of anionic dye (orange II) shows that it interferes with ISO when the concentration is 10 times larger than ISO.

3.4.6. Influence of ISO Concentration. The relationship between the oxidation peak current of ISO and the concentration was studied by SWV under optimized conditions (Figure 7). The peak current increases with the concentration of ISO over the range from $2 \times 10^{-8}$ to $1.8 \times 10^{-7} \mathrm{M}$. The relationship between these two parameters is linear, with a slope $(\mu \mathrm{A} / \mathrm{M})$ of 0.14 and a correlation coefficient of 0.998 . The detection limit for this work was estimated to be $1 \times 10^{-9} \mathrm{~mol} \mathrm{~L}^{-1}$ on the basis of signal-to-noise ratio equal to 3. A comparison of the performance of NiAl-LDH/CPE including the limit of detection and the linear range with those reported in the literature is shown in Table 3 which indicates that the proposed sensor exhibited detection limits lower than those reported by certain authors.

The analytical applicability of the modified electrode was applied to the determination of ISO in real sample. A volume of $50 \mathrm{~mL}$ of the spring water was first analyzed by using the optimized parameters established in this study and ISO was not detected. However, if these samples were spiked with $0.16 \mu \mathrm{mol} \mathrm{L}{ }^{-1}$ of ISO, the content was determined by the standard addition method (the results are summarized in Table 4). The obtained values are in good agreement with the spiked value, indicating that the proposed method is a good alternative for the analytical determination of this pesticide in the sample. 
TABLE 1: Optimum experimental conditions used in SWV of ISO.

\begin{tabular}{lcc}
\hline Instrumental parameter & Range examined & Optimum value \\
\hline Electrolysis potential $(\mathrm{mV})$ & -0.2 to 1.6 & 0.8 \\
Frequency $(\mathrm{Hz})$ & 25 to 220 & 125 \\
Amplitude $(\mathrm{V})$ & 25 to 100 & 50 \\
\hline
\end{tabular}

TABle 2: Effect of interference ions on the response of the NiAl-LDH/CPE to $25 \mu \mathrm{M}$ ISO in acetate buffer (pH 4.5).

\begin{tabular}{|c|c|c|}
\hline Interference ions & Added amount over [ISO] & $\%$ variation in the anodic peak current $(\mathrm{Ip}=100 \%)$ \\
\hline \multirow{3}{*}{$\mathrm{Cl}^{-}$} & 5 & 0 \\
\hline & 25 & +32.1 \\
\hline & 50 & +52.4 \\
\hline \multirow{3}{*}{$\mathrm{NO}_{3}{ }^{-}$} & 5 & 0 \\
\hline & 25 & +21.7 \\
\hline & 50 & +33.21 \\
\hline \multirow{3}{*}{ Orange II } & 10 & +10.9 \\
\hline & 25 & +21.4 \\
\hline & 50 & +54.45 \\
\hline $\mathrm{HCO}_{3}{ }^{-}$ & 50 & +33.26 \\
\hline $\mathrm{Al}^{3+}$ & 50 & -1.5 \\
\hline $\mathrm{Pb}^{2+}$ & 50 & -3 \\
\hline
\end{tabular}

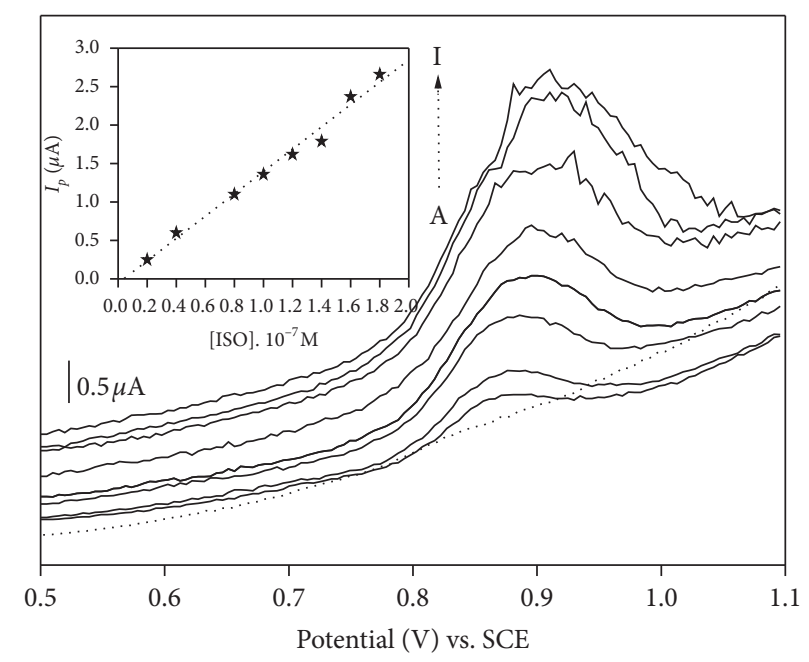

FIGURE 7: Dependence of the SWV peak current with increased ISO concentration from (a) to (i) $2 \times 10^{-8} ; 4 \times 10^{-8} ; 8 \times 10^{-8} ; 1 \times 10^{-7}$; $1.2 \times 10^{-7} ; 1.4 \times 10^{-7} ; 1.6 \times 10^{-7} ; 1.8 \times 10^{-7} \mathrm{M}$. The inset shows the corresponding calibration curve.

TABLE 3: Comparison of the proposed method with literature methods for the determination of phenyl urea herbicides.

\begin{tabular}{|c|c|c|c|}
\hline Electrode configuration & Linearity range $(\mathrm{M})$ & Detection limit $(\mathrm{M})$ & Ref \\
\hline Graphene modified $/{ }^{*} \mathrm{GCE}$ & $9.69 \times 10^{-8}-4.84 \times 10^{-5}$ & $9.69 \times 10^{-8}$ & [10] \\
\hline GO-MWCNT film-modified $/{ }^{*}$ GCE & $9 \times 10^{-6}-0.38 \times 10^{-3}$ & $0.645 \times 10^{-6}$ & {$[31]$} \\
\hline Polypyrrole/* GCE & $2.42 .10^{-9}-1.42 .10^{-6}$ & $2.42 \times 10^{-9}$ & {$[32]$} \\
\hline Sodium montmorillonite film $/{ }^{*} \mathrm{GCE}$ & $0.206 \times 10^{-6}-61.8 \times 10^{-6}$ & $0.206 \times 10^{-6}$ & {$[35]$} \\
\hline Organomontmorillonite/* GCE & $4.84 \times 10^{-9}-1.45 \times 10^{-6}$ & $4.84 \times 10^{-9}$ & {$[36]$} \\
\hline PANI/MWCNTs/* GCE & $4.84 \times 10^{-8}-4.84 \times 10^{-4}$ & $4.84 \times 10^{-10}$ & {$[37]$} \\
\hline Well-jet electrode & $4.84 \times 10^{-7}-7.27 \times 10^{-3}$ & $4.84 \times 10^{-7}$ & {$[38]$} \\
\hline $\mathrm{Ph}-\mathrm{CN}-\mathrm{SWCNT} /{ }^{*} \mathrm{GCE}$ & $1 \times 10^{-6}-2 \times 10^{-4}$ & $0.20 \times 10^{-6}$ & {$[39]$} \\
\hline $\mathrm{NiAl}-\mathrm{LDH} /{ }^{* *} \mathrm{CPE}$ & $2 \times 10^{-8}-1.8 \times 10^{-7}$ & $1 \times 10^{-9}$ & This work \\
\hline
\end{tabular}

${ }^{*}$ GCE: glassy carbon electrode. ${ }^{* *} \mathrm{CPE}$ : carbon paste electrode. GO-MWCNTs: graphene-multiwalled carbon nanotubes. PANI/MWCNTs: polyaniline multiwalled carbon nanotubes. Ph-CN-SWCNT: phthalocyanine-single walled carbon nanotube. 
TABLE 4: Determination of ISO in spring water.

\begin{tabular}{lccc}
\hline & ISO added $(\mathrm{M})$ & ISO found $(\mathrm{M})$ & Recovery (\%) \\
\hline Spring water & $0.160(\mu \mathrm{M})$ & $0.156 \pm 0.012 \mu \mathrm{M}$ & 97.5 \\
\hline
\end{tabular}

${ }^{\mathrm{a}}$ Number of samples assayed $=5$.

\section{Conclusion}

In this work, NiAl-LDH was shown to be effective material for the elaboration of an amperometric sensor for ISO. Prior to its use for sensing purposes, this material was characterized by X-ray diffraction, infrared spectroscopy, and thermal analysis. The determination of ISO was examined at a bare CPE and NiAl-modified CPE by using square wave voltammetric techniques. Results showed that the peak current was greatly enhanced (more that 2.6-fold) compared to the response obtained using bare CPE. It was also found that the sensitivity of this modified electrode depends on the loading of NiAl-LDH on the paste composition and mainly on the parameters involved in the detection step by square wave voltammetry. After optimization, a detection limit of 1x10-9 mol. $\mathrm{L}^{-1}$ was achieved. The proposed method was applied to quantify ISO in real media. The obtained results clearly indicated that the proposed voltammetric procedure could be applied for ISO sensing in environmental polluted media.

\section{Data Availability}

The data used to support the findings of this study are available from the corresponding author upon request.

\section{Conflicts of Interest}

The authors declare that they have no conflicts of interest.

\section{Acknowledgments}

Central ElectroChemical Research Institute (CECRI) is gratefully acknowledged for all facilities, as well the University of Maroua (Cameroon) for the financial support to Dr. Tcheumi Herve.

\section{Supplementary Materials}

Linear relation of anodic peak current against the square root of scan rate of $10^{-4} \mathrm{M}$ of $\left[\mathrm{Fe}(\mathrm{CN})_{6}\right]^{3-}$ in $\mathrm{KCl} 0.1 \mathrm{M}$ : (a) bare CPE and (b) NiAl-LDH/CPE. Insets were the CVs of bare EPC (a) and NiAl-LDH/CPE (b) in $10^{-4} \mathrm{M}\left[\mathrm{Fe}(\mathrm{CN})_{6}\right]^{3-}$ at different scan rates from 10 to $80 \mathrm{mVs}^{-1}$. (Supplementary Materials)

\section{References}

[1] C. Yi, Z. Shuang, and Y. Hong, "Acceleration of the herbicide isoproturon degradation in wheat by glycosyltransferases and salicylic acid," Journal of Hazardous Materials, vol. 283, pp. 806-814, 2015.

[2] L. Alletto, Y. Coquet, B. Pierre, and V. Bergheaud, "Effects of temperature and water content on degradation of isoproturon in three soil profiles," Chemosphere, vol. 64, no. 67, pp. 1053-1061, 2006.

[3] M. Chicharro, E. Bermejo, A. Sánchez, A. Zapardiel, A. Fernandez-Gutierrez, and D. Arraez, "Multiresidue analysis of phenylurea herbicides in environmental waters by capillary electrophoresis using electrochemical detection," Analytical and Bioanalytical Chemistry, vol. 382, no. 2, pp. 519-526, 2005.

[4] A. Wong, M. R. de Vasconcelos Lanza, and M. D. P. T. Sotomayor, "Sensor for diuron quantitation based on the P450 biomimetic catalyst nickel(II) 1,4,8,11,15,18,22,25octabutoxy-29H,31H-phthalocyanine," Journal of Electroanalytical Chemistry, vol. 690, pp. 83-88, 2013.

[5] M. Ren-Xiang, C. Ming-Xue, and Z. Jian-Liang, "Simultaneous determination of 15 phenylurea herbicides in rice and corn using HPLC with fluorescence detection combined with UV decomposition and post-column derivatization," Journal of Chromatography B, vol. 875, no. 2, pp. 437-443, 2008.

[6] Y. Wang, L. Xiao, and M. Cheng, "Determination of phenylureas herbicides in food stuffs based on matrix solid-phase dispersion extraction and capillary electrophoresis with electrochemiluminescence detection," Journal of Chromatography A, vol. 1218, no. 50, pp. 9115-9119, 2011.

[7] J. Fenoll, P. Hellín, C. M. Martínez, P. Flores, and S. Navarro, "High performance liquid chromatography-tandem mass spectrometry method for quantifying phenylurea herbicides and their main metabolites in amended and unamended soils," Journal of Chromatography A, vol. 1257, pp. 81-88, 2012.

[8] G. Shiqian, J. You, X. Zheng et al., "Determination of phenylurea and triazine herbicides in milk by microwave assisted ionic liquid microextraction high-performance liquid chromatography," Talanta, vol. 82, no. 4, pp. 1371-1377, 2010.

[9] P. A. Sundari and P. Manisankar, "Development of nano poly(3-methyl thiophene)/multiwalled carbon nanotubes sensor for the efficient detection of some pesticides," Journal of the Brazilian Chemical Society, vol. 22, no. 4, pp. 746-755, 2011.

[10] P. Noyrod, O. Chailapakul, W. Wonsawat, and S. Chuanuwatanakul, "The simultaneous determination of isoproturon and carbendazim pesticides by single drop analysis using a graphene-based electrochemical sensor," Journal of Electroanalytical Chemistry, vol. 719, pp. 54-59, 2014.

[11] D. H. Fuerte, M. Palomar-Pardavé, T. Jesús Licona-Sánchez, M. Romero-Romo, and J. S. Valente, "Electrochemical oxidation of 4-chlorophenol over a carbon paste electrode modified with ZnAl layered double hydroxides," Journal of the Mexican Chemical Society, vol. 58, no. 3, pp. 339-342, 2014.

[12] M. Kahl and T. D. Golden, "Electrochemical determination of phenolic acids at a $\mathrm{Zn} / \mathrm{Al}$ layered double hydroxide film modified glassy carbon electrode," Electroanalysis, vol. 26, no. 8, pp. $1664-1670,2014$.

[13] B. Nadeem and S. Muhammad, "Applications of layered double hydroxides based electrochemical sensors for determination of environmental pollutants: a review," Trends in Environmental Analytical Chemistry, vol. 16, pp. 1-15, 2017.

[14] I. M. Isa, M. R. Fasyir, N. Hashim et al., "A highly sensitive mercury (II) sensor using $\mathrm{Zn} / \mathrm{Al}$ layered double hydroxide3(4-hydroxyphenyl) propionate modified multi-walled carbon nanotube paste electrode," Journal of Solid State Electrochemistry, vol. 10, pp. 6227-6240, 2015.

[15] L. Jin, D. He, and M. Wei, "Selective adsorption of phenol and nitrobenzene by $\beta$-cyclodextrin-intercalated layered double 
hydroxide: equilibrium and kinetic study," Chemical Engineering \& Technology, vol. 34, no. 9, pp. 1559-1566, 2011.

[16] S. Carlino, "The intercalation of carboxylic acids into layereddouble hydroxides: a critical evaluation and review of the differentmethods," Solid State Ionics, vol. 98, no. 1-2, pp. 73-84, 1997.

[17] J. Gong, T. Liu, X. Wang, X. Hu, and L. Zhang, "Efficient removal of heavy metal ions from aqueous systems with the assembly of anisotropic layered double hydroxide nanocrystals@carbon nanosphere," Environmental Science \& Technology, vol. 45, no. 14, pp. 6181-6187, 2011.

[18] X. Zhang, J. Bai, and H.-M. Zhang, "Synthesis of nanosized LDHs by Au colloidal nanoparticles as nuclei and its application for electroanalysis," Applied Clay Science, vol. 119, no. 2, pp. 410-416, 2016.

[19] A. P. W. Kameni, H. L. Tcheumi, I. K. Tonle, and E. Ngameni, "Sensitive electrochemical detection of methyl parathion in the presence of para-nitrophenol on a glassy carbon electrode modified by a functionalized NiAl-layered double hydroxide," Comptes Rendus Chimie, vol. 22, no. 1, pp. 22-33, 2019.

[20] K. S. Guha, R. J. Mascarenhas, T. Thomas, and O. J. D’Souza, "Differential pulse anodic stripping voltammetric determination of $\mathrm{Hg} 2+$ at poly(eriochrome black $\mathrm{T}$ )-modified carbon paste electrode," Ionics, vol. 20, no. 6, pp. 849-856, 2014.

[21] V. Rives, In Layered Double Hydroxides: Present and Future, V. Rives, Ed., p. 139, Nova Science Publishers Inc., New York, NY, USA, 2001.

[22] M. Jitianu, M. Bãlãsoiu, R. Marchidan, M. Zaharescu, D. Crisan, and M. Craiu, "Thermal behaviour of hydrotalcitelike compounds: study of the resulting oxidic forms," Inter. J. Inorg. Mater, vol. 2, no. 2-3, pp. 287-300, 2000.

[23] Z. P. Xu and H. C. Zeng, "Abrupt structural transformation in hydrotalcite-like compounds $\mathrm{Mg} 1-\mathrm{xAlx}(\mathrm{OH}) 2(\mathrm{NO} 3) \mathrm{x} \cdot \mathrm{nH} 2 \mathrm{O}$ as a continuous function of nitrate anions," The Journal of Physical Chemistry B, vol. 105, no. 9, pp. 1743-1749, 2001.

[24] Z. P. Xu, G. Stevenson, C.-Q. Lu, and G. Q. Lu, "Dispersion and size control of layered double hydroxide nanoparticles in aqueous solutions," The Journal of Physical Chemistry B, vol. 110, no. 34, pp. 16923-16929, 2006.

[25] G. A. Caravaggio, C. Detellier, and Z. Wronski, "Synthesis, stability and electrochemical properties of $\mathrm{NiAl}$ and $\mathrm{NiV}$ layered double hydroxides," Journal of Materials Chemistry, vol. 11, no. 3, pp. 912-921, 2001.

[26] F. R. Costa, A. Leuteritz, U. Wagenknecht, D. Jehnichen, L. Häußler, and G. Heinrich, "Intercalation of Mg-Al layered double hydroxide by anionic surfactants: preparation and characterization," Applied Clay Science, vol. 38, no. 3-4, pp. 153-164, 2008.

[27] O. Clause, M. Gazzano, F. Trifiro' ${ }^{\prime}$ A. Vaccari, and L. Zatorski, "Preparation and thermal reactivity of nickel/chromium and nickel/aluminium hydrotalcite-type precursors," Applied Catalysis, vol. 73, no. 2, pp. 217-236, 1991.

[28] O. Clause, B. Rebours, E. Merlen, F. Trifiro, and A. Vaccari, "Preparation and characterization of nickel-aluminum mixed oxides obtained by thermal decomposition of hydrotalcitetype precursors," Journal of Catalysis, vol. 133, no. 1, pp. 231-246, 1992.

[29] M. Li, F. Ni, Y. Wang, S. Xu, D. Zhang, and L. Wang, "LDH modified electrode for sensitive and facile determination of iodatefied electrode for sensitive and facile determination of iodate," Applied Clay Science, vol. 46, no. 4, pp. 396-400, 2009.

[30] B. Ballarin, M. Gazzano, R. Seeber, D. Tonelli, and A. Vaccari, "Electrodes coated by hydrotalcite-like clays. effect of the metals and the intercalated anions on ion accumulation and retention capability," Journal of Electroanalytical Chemistry, vol. 445, no. 1-2, pp. 27-37, 1998.

[31] V. Mani, R. Devasenathipathy, S.-M. Chen, T.-Y. Wu, and K. Kohilarani, "High-performance electrochemical amperometric sensors for the sensitive determination of phenyl urea herbicides diuron and fenuron," Ionics, vol. 21, no. 9, pp. 2675-2683, 2015.

[32] P. Manisankar, G. Selvanathan, and C. Vedhi, "Utilisation of polypyrrole modified electrode for the determination of pesticides," International Journal of Environmental Analytical Chemistry, vol. 85, no. 6, pp. 409-422, 2005.

[33] D. N. Teadoum, S. K. Noumbo, K. T. Arnaud, T. T. Ranil, A. D. Mvondo Zé, and I. K. Tonle, "Square wave voltammetric determination of residues of carbendazim using a fullerene/ multiwalled carbon nanotubes/nafion/coated glassy carbon electrode," International Journal of Electrochemistry, vol. 2016, pp. 1-9, 2016.

[34] A. J. Bard and L. R. Faulkner, Electrochemical MethodsFundamentals and Applications, John Wiley \& Sons, New York, NY, USA, 1980.

[35] P. Manisankar, G. Selvanathan, and C. Vedhi, "Utilization of sodium montmorillonite clay-modified electrode for the determination of isoproturon and carbendazim in soil and water samples," Applied Clay Science, vol. 29, no. 3-4, pp. 249-257, 2005.

[36] P. Manisankar, G. Selvanathan, and C. Vedhi, "Determination of pesticides using heteropolyacid montmorillonite claymodified electrode with surfactantfied electrode with surfactant," Talanta, vol. 68, no. 3, pp. 686-692, 2006.

[37] P. Manisankar, P. A. Sundari, R. Sasikumar, and S. Palaniappan, "Electroanalysis of some common pesticides using conducting polymer/multiwalled carbon nanotubes modified glassy carbon electrodefied glassy carbon electrode Talanta," Talanta, vol. 76, no. 5, pp. 1022-1028, 2008.

[38] P. Manisankar, G. Selvanathan, S. Viszanathan, and H. Gurumallesh Prabu, "Electrochemical determination of some organic pollutants using," Electroanalysis, vol. 14, no. 24, pp. 1722-1727, 2002.

[39] T. Mugadza and T. Nyokong, "Electrochemical, microscopic and spectroscopic characterization of benzene diamine functionalized single walled carbon nanotube-cobalt (II) tetracarboxy-phthalocyanine conjugates," Journal of Colloid and Interface Science, vol. 354, no. 2, pp. 437-447, 2011. 